\title{
O TRABALHADOR NO PROGRAMA SAÚDE DA FAMÍLIA NO INTERIOR DO ESTADO DO AMAZONAS: UM ESTUDO QUALITATIVO
}

\author{
THE WORKER IN THE FAMILY HEALTH PROGRAM IN THE STATE OF AMAZONAS: A QUALITATIVE STUDY \\ EL TRABAJADOR EN EL PROGRAMA SALUD DE LA FAMILIA EN EL INTERIOR DEL ESTADO DE \\ AMAZONAS: UN ESTUDIO CUALITATIVO
}

\author{
Marilise Katsurayama ${ }^{1}$ \\ Rosana Cristina Pereira Parente ${ }^{2}$ \\ Rodrigo Otávio Moretti-Pires ${ }^{3}$
}

Resumo Este artigo traz uma análise da relação trabalho-subjetividade na Estratégia Saúde da Família no interior do estado do Amazonas, sob a perspectiva da psicodinâmica do trabalho, segundo a qual o trabalho é aquilo que demanda, além do saber-fazer, engajamento do corpo e mobilização da inteligência, a capacidade de refletir, criar e inventar. Propôs-se, a partir daí, uma análise do que é invisível no trabalho, com base nas falas de 75 profissionais da saúde na Estratégia Saúde da Família de quatro municípios do Estado do Amazonas (Coari, Manacapuru, Parintins e São Gabriel da Cachoeira), obtidas por meio de entrevistas individuais, grupos focais e observação participante. Foram identificados diferentes conteúdos significativos do trabalho, ou seja, o sentido simbólico que ele introduz na sua atividade de trabalho, além de estratégias defensivas para a mediação do sofrimento, entre elas a racionalização e a relação de confiança e cooperação encontrada na equipe. Os trabalhadores da Estratégia Saúde da Família na Amazônia mostraram enfrentar questões peculiares quanto aos serviços de saúde desses locais. Por meio desta pesquisa qualitativa, pudemos dar voz ao trabalhador, considerando-o como o principal gestor de seu próprio trabalho, permitindo através da reflexão vislumbrar seu potencial de gerar mudanças a partir do trabalho cotidiano. Palavras-chave trabalhadores; serviços de saúde; saúde da família.
Abstract This article analyzes the relationship between work and subjectivity in the Family Health Strategy in the state of Amazonas, Brazil, from the perspective of the psychodynamics of work, pursuant to which work is what imposes demands, in addition to know-how, the engagement of the body and mobilization of intelligence, the ability to reflect, create, and invent. From there, it was proposed an analysis of those things that are invisible at work, based on the statements of 75 health professionals working in the Family Health Strategy at four municipalities in the state of Amazonas (Coari, Manacapuru, Parintins, and São Gabriel da Cachoeira), obtained via individual interviews, focus groups, and participant observation. Different types of significant labor content have been identified, i.e., the symbolic sense that it introduces in one's work activity, in addition to defensive strategies for the mediation of suffering, including the rationalization and the relationship of trust and cooperation found in the team. The Family Health Strategy workers in Amazonas showed they come up against unique issues in the provision of health services at these locations. Through this qualitative survey, we give voice to the workers, considering them as the main managers of their own work, allowing, through reflection, them to envision their potential to create change from their daily work.

Keywords Workers; health services; family health. 


\section{Introdução}

A literatura revela que a visitação aos serviços de saúde modula-se a partir da interação de variados fatores, tais como demográficos, socioeconômicos, aspectos psicológicos e a estrutura dos próprios serviços de saúde, sendo que a efetividade e importância relativa de cada um desses fatores estão na dependência do aporte cultural, das políticas de saúde e da possibilidade dos sistemas de saúde (Mendonza-Sassi, Béria e Barros, 2003). Diante disso, é possível afirmar que na região Amazônica diversos aspectos do Sistema Único de Saúde (SUS) se configuram de maneira peculiar em relação à forma que tomam em outras partes do Brasil.

A efetivação da Estratégia Saúde da Família (ESF) no contexto do interior do estado do Amazonas, independente da questão de acesso, é de suma importância para sua implementação na região, na medida em que, segundo o Ministério da Saúde, as pessoas que vivem em uma comunidade compartilham, ao longo do tempo, da construção histórico-social e cultural, da ocupação e estruturação de um território, ou seja, das suas condições de vida. Estas se traduzem nas características da reprodução biológica, nas relações de proteção/depredação do ambiente físico, nas concepções, valores que norteiam as decisões e as práticas cotidianas, e nas suas relações de produção e consumo de bens e serviços, moradia, saneamento básico, educação, saúde, emprego, transporte, comunicação e lazer (Brasil, 2000).

Frente às peculiaridades da região no que tange à inserção em uma equipe de trabalho como a ESF, a pesquisa aqui tratada teve como objetivo a análise desta relação escolhendo como foco o trabalho na ESF em quatro municípios do interior do estado do Amazonas pela perspectiva da psicodinâmica do trabalho conforme conceituado no marco teórico dejouriano. De acordo com a psicodinâmica do trabalho, a análise da relação trabalho-subjetividade sugere que o trabalho de ofício engaja toda a subjetividade (Dejours, 1993; Dejours, 2004).

O trabalho no que ele tem de essencial não pertence ao mundo visível, pois o sofrimento, como tudo que é afetivo, é a origem da inteligência e constitui a própria substância do trabalhar, sendo, portanto, inacessível a quantificação. Portanto, o trabalho não pode ser objeto de uma avaliação objetiva, pois, segundo Dejours (2004), só aquilo que pertence ao mundo visível é acessível à experimentação científica.

Esta dificuldade se agrava no momento em que as atividades de trabalho evoluem na direção de tarefas imateriais, ou seja, quando não há a produção de objetos materiais, mas, em que o objetivo principal a ser alcançado com o trabalho é a promoção da saúde da comunidade por meio da prevenção de patologias. Então, a parte mais importante do trabalho efetivo é invisível, e sem a exploração da relação trabalho e subjetividade uma importante parte 
do trabalho efetivo permanece na sombra, não sendo passível de avaliação (Dejours, 2004).

Segundo a psicodinâmica do trabalho, o trabalho não é redutível a uma atividade de produção no mundo objetivo; para a subjetividade, trabalhar constitui uma provação que a transforma, não é somente produzir, é transformar a si mesmo e, assim, oferecer à subjetividade uma oportunidade para se testar ou, até mesmo, se realizar (Dejours, 2004).

O objeto de atenção dessa pesquisa dentro do cenário supracitado delimitou-se à dimensão sociopsíquica do trabalho mediante uma análise clínica da relação entre subjetividade e trabalho, descrita por Dejours (apud Mendes, 2007). Portanto, a finalidade dessa pesquisa pautou-se na confrontação do sujeito com a realidade do trabalho, partindo dos processos psíquicos envolvidos, voltando para o interesse das vivências subjetivas dos sujeitos, a intersubjetividade que permeia o trabalho e o lugar ocupado pelo trabalho nos processos de regulação psíquica (Dejours, Abdoucheli, Jayet, 1994).

\section{Diversidade sociocultural e geográfica da região e formas de abordagem qualitativa do trabalho}

A pesquisa ${ }^{4}$ foi conduzida no estado do Amazonas no segundo semestre de 2009, nos municípios de Coari, Manacapuru, Parintins e São Gabriel da Cachoeira, momento em que alterações climáticas promoveram enchentes seguidas de dificuldades socioeconômicas vividas pelas populações desses municípios. Os municípios foram escolhidos pela diversidade sociocultural e geográfica existentes entre si. Para atingir os objetivos propostos, o estudo se pautou em métodos que congregam o levantamento de informações de cunho qualitativo (entrevista individual, grupo focal com roteiro semiestruturado e observação participante).

O estado do Amazonas é constituído por 62 municípios e conta com uma população de 3.341 .096 habitantes distribuídos numa área de $1.570 .745,680 \mathrm{~km}^{2}$. O município de Coari abrange uma área de $57.230 \mathrm{~km}^{2}$, com 66.991 habitantes. É conhecido pela produção de banana e pela região produtora de petróleo e gás natural chamada Urucu. Outro fato importante é que está sendo construído um gasoduto que ligará sua província produtora ao mercado consumidor localizado em Manaus. O acesso à região é somente aéreo e fluvial (IBGE, 2008).

A população de Manacapuru é de 86.472 habitantes distribuídos numa área de $7.329,23 \mathrm{~km}^{2}$. O meio de transporte mais utilizado é o rodoviário, já que o acesso a partir de Manaus se dá por rodovia asfaltada (84 km de distância) (Instituto Brasileiro de Geografia e Estatística, 2008).

O município de Parintins tem uma área de $5.952 \mathrm{~km}^{2}$ e dista 315 quilômetros de Manaus. Conta com 107.250 habitantes e se configura como o 
segundo maior município do estado e um dos pontos turísticos mais importantes da Amazônia. Lá é realizado o Festival Folclórico de Parintins, um dos principais patrimônios culturais e festivais da América Latina (Instituto Brasileiro de Geografia e Estatística, 2008).

São Gabriel da Cachoeira abrange uma área de $109.185 \mathrm{~km}^{2}$, distando $852 \mathrm{~km}$ da capital Tem uma população de 41.885 habitantes e situa-se no extremo noroeste do estado do Amazonas, na bacia do Alto Rio Negro. É o município com maior número de indígenas no país, e a primeira cidade brasileira a escolher prefeito e vice-prefeito indígenas (Instituto Brasileiro de Geografia e Estatística, 2008).

Nesses municípios, a pesquisa se estendeu a pelo menos três equipes de Saúde da Família em cada um deles. Participaram da pesquisa 13 médicos, 14 enfermeiros, 12 dentistas, 13 técnicos (técnicos de enfermagem, técnicos de laboratório, técnicos de planejamento, recepcionistas, e assistentes de cirurgião-dentista [ACDs]) e 23 agentes comunitários de saúde (ACSs).

As entrevistas individuais foram realizadas com todos os profissionais da ESF presentes no momento da coleta: médicos, dentistas, enfermeiros, técnicos (de enfermagem e laboratório), ACSs, ACDs, seguindo o roteiro de entrevista semiestruturado específico para esses sujeitos. Ao todo foram realizadas 75 entrevistas individuais por uma equipe de três profissionais graduados em área da saúde, com duração média de trinta minutos.

O grupo focal seguiu um roteiro previsto e foi realizado em cada Unidade Básica de Saúde (UBS) com a maior quantidade de profissionais presentes no momento da coleta, devendo ser presença obrigatória: médico, enfermeiro e no mínimo três ACSs. Foram realizados ao todo 15 grupos focais, tendo a duração mínima de quarenta minutos e máxima de noventa minutos, totalizando mais de 15 horas de gravação.

Para ambas as técnicas (entrevista individual e grupo focal), a literatura aponta a necessidade de características ímpares que norteiem o estabelecimento dos critérios de inclusão dos sujeitos, devendo-se obedecer a premissa da existência de, pelo menos, uma característica comum e de interesse, determinada pelo objetivo da investigação. A amostra é, portanto, considerada intencional. A principal forma de registro, tanto para o grupo focal quanto para as entrevistas individuais, foi o sonoro digital.

$\mathrm{Na}$ análise dos grupos focais o material produzido foi considerado como um produto coletivo e não oriundo do indivíduo, visando fornecer tendências, padrões ou parâmetros a partir dos comentários selecionados, assim como opiniões mantidas e expressas frequentemente, destacando-se as falas relacionadas às questões norteadoras para constituírem categorias. Assim, preponderou o caráter coletivo como unidade de análise, a partir da construção do produto, não indicada para determinar os pontos de vistas autênticos dos indivíduos, mas sim o que foi possível construir frente ao outro e 
aos outros. Na etapa da interpretação, o produto final, depois de tratado, foi confrontado com os pressupostos do marco teórico que originou a pesquisa, tomando-o como parâmetro para análise. Cabe ressaltar que, na medida em que o produto dos grupos focais apresentou o caráter coletivo já referido, optou-se por não identificar os sujeitos na apresentação dos resultados, mas sim a que grupo focal pertenciam.

A escolha pela técnica do grupo focal coincidiu com a proposta metodológica dejouriana que privilegia o contexto coletivo, sendo todo o processo de coleta de dados realizado no local de trabalho ou em um espaço físico a ele relacionado (Dejours, 2004). O grupo focal produziu respostas que refletem a perspectiva do funcionamento do grupo, do processo de trabalho; enquanto as entrevistas individuais refletem a perspectiva individual do trabalhador que, quando analisadas sistematicamente por meio da técnica de análise proposta, permitem articular as diferenças e semelhanças com relação ao trabalho realizado na ESF. No entanto, ressalta-se que, diferente do caráter coletivo dos grupos focais, o produto originado nas entrevistas individuais é pertinente ao próprio entrevistado. Portanto, há a necessidade de identificar falas e respectivos sujeitos que as formularam, pois revela a dimensão individual sobre a temática investigada (Minayo, 1996).

Já a técnica da observação participante correspondeu neste estudo ao que Dejours (1987) definiu como observação clínica, que consiste no material essencial para a elaboração e a discussão psicopatológicas, visto que o sofrimento e o prazer somente podem ser identificados através da subjetividade de um receptor do discurso, ação que Dejours chama de objetivação da intersubjetividade. É com essa técnica que é possível evidenciar a movimentação, os desvios, as reações que surgem, permitindo a explicitação do caminho tomado pelo pensamento do pesquisador (Dejours, 1987)

A observação se pautou em roteiro prévio, tentando identificar outras dimensões não previstas inicialmente, em especial no que concerne ao processo de trabalho em Saúde da Família. Além do ato de observar em si, foi promovida entrevista não estruturada com base nos aspectos de interesse, tanto com os profissionais quanto com os usuários no serviço.

O tratamento e exame do produto empírico oriundo do grupo focal, entrevistas individuais e observação foram por meio da análise hermenêutica-dialética proposta por Minayo (1996). Segundo a autora, corresponde à análise "mais capaz de dar conta de uma interpretação aproximada da realidade" (Minayo, 1996, p. 231), pois coloca a fala em seu contexto para entendê-la a partir de seu interior e no campo da especificidade histórica e totalizante em que é produzida.

Assim, segundo Minayo (1996), é por intermédio de uma prática dialética interpretativa que se reconhecem os fenômenos sociais sempre com resultados e efeitos da atividade criadora, tanto imediata quanto institucionalizada, 
tornando como centro de análise a prática social, a ação humana que "atravessa o meio social, conserva as determinações, mas também transforma o mundo sobre as condições dadas" (Minayo, 1996, p. 232).

O estudo foi submetido à avaliação e aprovação pelo Comitê de Ética em Pesquisa da Universidade Federal de Santa Catarina (UFSC) (Protocolo ético n. 121/2009). Todo e qualquer procedimento de coleta de informação somente foi realizado após autorização das secretarias municipais de saúde envolvidas e leitura/explicação do termo de consentimento livre e esclarecido aos participantes.

\section{O conteúdo significativo do trabalho: investimentos simbólicos}

Com relação ao motivo que levou os profissionais à escolha da realização de atividades no nível da atenção básica, os discursos estiveram divididos em dois grandes grupos de fatores motivadores. O primeiro grupo compreende os trabalhadores que têm a satisfação em trabalhar com atividades de prevenção e promoção de saúde, bem como de estar em contato direto com a comunidade. Dados que são sustentados pelas falas que seguem:

O que eu gosto mesmo é essa coisa do cuidado, da freqüência com que a pessoa tem com a família (Médico 02 - Coari).

É uma questão de contato também, a gente consegue acompanhar o desenvolvimento da saúde das famílias, da comunidade. A comunidade tá bem mais próxima do que era antigamente, tem as campanhas, então hoje eu vejo com bons olhos o advento da saúde da família, né? (Médico 02 - São Gabriel da Cachoeira).

No interior tem carência de profissional, no interior tem como ter o diferencial, aqui a gente faz a diferença, enquanto que na capital a gente é mais um (...), o paciente muda de endereço e você não sabe mais nada e aqui não, aqui é diferente, a gente vê as crianças crescerem. É até engraçado porque a gente vê a 'criançadinha' que a gente atendeu com cinco anos, chega em você: 'Oi tia!' E quando você olha é um 'baita' garoto, e eles falam: 'Olha, tia, eu continuo escovando os dentes; Olha, tia, não tive mais cárie. Então, é gratificante esse trabalho (Dentista 03 - Parintins).

Ainda no primeiro grupo estão os profissionais que citam a identificação com a proposta, credibilidade na sua eficácia e em seu poder de transformação, além do sentimento de utilidade para a melhoria da saúde da população de seu município de origem, como os grandes fatores motivadores da sua inserção na atenção básica no interior do estado. Dados que se concretizam nas falas: 
Sempre trabalhei pro lado voltado pra saúde pública, trabalhei na saúde indígena, me identifiquei bastante, tem um laço com os colegas que fazem parte da equipe e como eu vim de uma família simples, humilde, eu sempre procurei cooperar (...) então é uma contribuição muito boa (Médico 01 - Manacapuru).

É o trabalho que eu me identifico. Primeiro, porque eu fiz a especialização e mestrado em odontologia preventiva e social, então eu me identifico muito (Dentista $01-$ Coari).

Sempre pensei que sendo médico eu poderia voltar e transformar a realidade, como coariense, (...) tentar transformar mesmo, (...) tentar ajudar a população da melhor forma (Médico 03 - Coari).

Sou de família muito pobre, (...) e via e vejo uma oportunidade de trabalhar com isto e me coloquei à disposição pra atender, uma vez que já aconteceu comigo, não tinha onde ficar, não tinha ninguém (...), a razão então foi social (Dentista 01 - Manacapuru).

O segundo grupo tem como fatores motivadores a necessidade de sustentação financeira, necessidade de complementar a renda, falta de perspectiva de emprego diante da falta de especialização. Como pode ser visto nas falas a seguir:

Porque eu me formei, foi a opção que eu tive (...) (Enfermeiro 03 - Coari).

É uma oportunidade, primeiro porque eu me formei recentemente nesse ano e essa foi a oportunidade que surgiu pra mim (Médico 02 - Manacapuru).

(...) pra complementar a renda (...) ajuda nosso trabalho no hospital (Médico $01-$ Parintins).

Para Ronzani (2001), o trabalho em Saúde da Família tem um talhe diferenciado, dado sua proposta, que, além da necessidade de capacidade técnica, os profissionais das equipes necessitam identificação com a proposta de trabalho que demanda criatividade, iniciativa e vocação, haja vista as características deste modelo.

Diante da teoria dejouriana, ao mesmo tempo em que a atividade de trabalho envolve uma significação narcísica, ela comporta os investimentos simbólicos e materiais destinados 'a um outro', o 'Objeto'. Portanto, o conteúdo significativo do trabalho em relação ao objeto pode veicular certo número de símbolos através dos gestos que ela implica, dos instrumentos que ela movimenta, da atmosfera na qual ela opera. A natureza e encadeamento 
desses símbolos dependem, por sua vez, da vida interior do sujeito, do sentido simbólico que ele introduz na sua atividade de trabalho, essas significações podem ser tanto concretas, direcionadas a um objeto exterior e real, quanto abstratas, direcionadas a um objeto interiorizado por outro, cujo papel é decisivo na vida (Mendes, 2007). Portanto, no conteúdo significativo do trabalho consideram-se dois componentes: o conteúdo significativo em relação ao Sujeito e o conteúdo significativo em relação ao Objeto (Dejours, 1987).

As significações concretas encontradas nas falas em sua maioria dizem respeito à sustentação financeira (meio de complementar a renda, primeira ou melhor oportunidade de emprego). As significações abstratas relacionam-se a sonhos e projetos de realizações possíveis, além do desejo de ajudar a população adscrita dada a identificação com o município, na maioria das vezes devido à sua naturalidade (pertencer ao município onde trabalha).

Toda essa significação abstrata “põe em questão a vida passada e presente do sujeito, sua vida íntima e sua história pessoal. De maneira que, para cada trabalhador, esta dialética do Objeto é específica e única" (Mendes, 2007, p. 50).

Um número considerável de profissionais trouxe como motivo principal de trabalharem na ESF o fato de serem recém-formados e esta ter sido a única ou melhor oportunidade de emprego na condição em que se encontravam. Questiona-se a partir daí a identificação desse trabalhador com a proposta, bem como sua motivação para trabalhar na ESF, podendo implicar um comprometimento na satisfação pessoal do profissional e falta de dedicação para a realização das atividades da proposta. Dado que, segundo Mendes (2007), a motivação pode ser a produção do desejo, ou o desejo o cerne da motivação, ou ainda, o desejo ser a parte inconsciente e oculta da motivação. Como diria Kurt Lewin (1940), a motivação está sempre lá para mostrar, quando ela está presente, a intencionalidade de um comportamento, esgotando seu sentido no prazer ou na ausência de dor, como complementa Saint-Girons (1968) (Mendes, 2007).

Ainda, diante das adversidades habituais do trabalho no setor público relacionadas aos mais diversos aspectos (infraestrutura, salário, vínculos, direitos), mobilizam e desestabilizam os investimentos e interesses (profissionais, subjetivos e afetivos) dos trabalhadores provocando-os e desafiando-os à tomada de uma atitude. Compreende-se, portanto, que essas atitudes serão de acordo com as significações concretas e abstratas construídas pelo trabalhador acerca de sua atividade de trabalho. Sugere-se, assim, que o indivíduo que se identifica e acredita na proposta está mais motivado a tomar atitudes como superação, improvisação, encontrando saídas 'criativas' e 'inventivas', enquanto o outro grupo poderá tomar atitudes de negação, recuo e resistência, resultando possivelmente em condições desgastantes, geradoras de sofrimento (Santos-Filho e Barros, 2007). 
Como confirma Dejours (1987, p. 49), “executar uma atividade sem investimento material ou afetivo exige produção de esforço e de vontade, em outras circunstâncias suportadas pelo jogo da motivação e do desejo".

Além de capacidade técnica e identificação com a proposta, o trabalho deve ocorrer sob a organização em equipe, imergindo na realidade das famílias da área adscrita. A rotina e o processo de trabalho, por consequência, serão diferenciados em relação ao modelo de atenção primária tradicional, exigindo capacitação da equipe para esta nova realidade. Do contrário, somam-se ações individuais isoladas, que não configuram o trabalho genuinamente em equipe (Ronzani, 2001).

A afirmação de Ronzani (2001) vai de encontro aos resultados dessa pesquisa. Enquanto o profissional da ESF deveria priorizar o vínculo com o paciente e a família, para um melhor acompanhamento do paciente/família, melhor adesão ao tratamento, melhor desenvolvimento da autonomia destes, os profissionais que encontramos no interior do estado do Amazonas apresentaram uma intensa rotatividade. Havia médicos que tinham assumido a função há menos de 15 dias, não sendo capazes dessa forma de conhecer a realidade da população adscrita, nem tampouco estabelecer o vínculo necessário na relação médico-paciente e indispensável na atenção básica, além de profissionais que acabavam de deixar definitivamente seu posto de trabalho, sem, no momento, ter sido substituído por outro profissional. Nesses casos, fica comprometida a organização do trabalho no que se refere ao trabalho multiprofissional que necessita de uma relação de ajuda mútua e boa interatividade entre os diferentes profissionais, refletindo na qualidade do atendimento da população, bem como há um déficit na composição do quadro de profissionais atuantes, que, por sua vez, vem a refletir na sobrecarga de trabalho para esses trabalhadores.

Segundo Nascimento e Costa (apud Cohn, 2009):

Nas grandes cidades os trabalhadores dessas unidades exercem atividades longe do seu local de moradia, e até mesmo em outros municípios. Como decorrência, a rotatividade de profissionais é muito intensa, uma vez que estão sempre à procura de postos de trabalho próximos de suas residências, comprometendo assim a lógica de fixação de equipes no território e a consequente consolidação da nova organização de trabalho (Cohn, 2009, p. 83).

Além do mais, grande quantidade de profissionais (em sua maioria médicos) que participaram da pesquisa era de outros estados do Brasil, inseridos na ESF pela melhor oportunidade de emprego fora da cidade natal. Havia inclusive um profissional de outro país que ao menos conseguia compreender algumas perguntas ou mesmo ser compreendido em suas respostas. Reforça-se com isso a necessidade de se conhecer melhor a cultura regional 
por meio de uma imersão na realidade dessas famílias. Para isso, é importante que o profissional se comprometa e se dedique à realização da proposta.

\section{Estratégias defensivas diante do sofrimento: uma tentativa de alcançar o prazer}

Diante das dificuldades relatadas pelos profissionais (falta de estrutura, medicamentos, recursos humanos) dos municípios do interior do estado, o profissional muitas vezes se vê na impossibilidade de rearranjar a organização do trabalho. A partir daí, Dejours defende que a não canalização da descarga da energia pulsional no exercício do trabalho levará a um acúmulo no aparelho psíquico, ocasionando um sentimento de desprazer e tensão. Se este acúmulo permanece por muito tempo, as capacidades de conter esses sentimentos transbordam, desencadeando perturbações somáticas (tradução somática) (Dejours, 1993).

Segundo Dejours,

De uma relação desarmoniosa entre o conteúdo ergonômico do trabalho (exigências físicas, químicas, biológicas) e a estrutura da personalidade pode emergir uma insatisfação e, correlativamente, um sofrimento que são de natureza mental e não física (Dejours, 1987, p. 57).

Autores como Beck (2000), Ferreira e Mendes (2001; 2003) e Morrone (2001) confirmam ser a falta de infraestrutura um aspecto dificultador da produção e gerador de sofrimento. Portanto, com a finalidade de enfrentar esse sofrimento, o trabalhador da ESF busca estratégias inconscientes com a finalidade de tentar neutralizar os aspectos negativos do trabalho e eufemizar o sofrimento, ou seja, estratégias que possam aliviar a dor, a frustração, o sentimento de impotência diante da demanda que o procura. Na pesquisa realizada foram identificadas algumas estratégias defensivas para a mediação do sofrimento. Uma delas foi a racionalização, ou seja, a busca de explicações lógicas para se continuar trabalhando.

Quando questionados sobre o seguimento ou não do que é preconizado pelo SUS ao funcionamento ideal da ESF, alguns profissionais demonstraram uma atitude de contentamento com as más condições de trabalho (em termos quantitativos e qualitativos), emergindo através de expressões como “a gente faz o que pode", "fazemos o que está ao nosso alcance", "fazemos nossa parte na medida do possível". Verifica-se nesses recortes uma estratégia defensiva para evitar o sofrimento iminente diante da frustração e sentimento de impotência na dificuldade para a realização de seu trabalho. Dessa forma, diante do real do trabalho, o profissional, ao fugir do sofrimento, exime sua culpa no não cumprimento do que está prescrito. Como evidenciado na fala a seguir: 
Era pra ter três equipes; não tá funcionando, os profissionais não estão aqui, não sei o motivo por que não estão. Então, a gente tem que se desdobrar pra cobrir outra área, tem algumas coisas que são deficientes e pra funcionar como o SUS idealiza depende só dos nossos gestores, não depende da gente (Grupo Focal 01 Manacapuru).

Parafraseando Dejours (1987), a ideologia defensiva não é dirigida contra uma angústia proveniente de conflitos intrapsíquicos de natureza mental, mas sim contra perigo e riscos reais. É tão inevitável quanto obrigatória, pois substitui os mecanismos de defesa individuais. Como complementa Dejours, a ideologia defensiva

tem por objetivo mascarar, conter, ocultar uma ansiedade particularmente grave. (...) é a nível da ideologia defensiva, enquanto mecanismo de defesa elaborado por um grupo social particular, que devemos procurar uma especificidade (Dejours, 1987, p. 36).

A diversidade de estratégias a serem utilizadas pelos trabalhadores para minimizar o sofrimento depende, em grande parte, da relação de trabalho, ou seja, de todos os laços humanos criados pela organização do trabalho (relações com hierarquia, com a supervisão, com os outros trabalhadores). Esta relação pode, por um lado, ser fonte suplementar de sofrimento, porém não é o que acontece nas unidades pesquisadas. Para lidar com o real do trabalho, as dificuldades e adversidades encontradas no dia a dia da equipe, o grupo precisa se fortalecer nesta relação de confiança e cooperação (Dejours, 1987; 1997).

Ainda complementa Dejours (apud Santos-Filho e Barros):

(...) o processo de cooperação é a base para a constituição de uma equipe; é aquilo que funda o coletivo de trabalho. E é pela cooperação que um coletivo torna-se eficiente e eficaz, além de ter seus 'erros' e 'riscos' minimizados (Santos-Filho e Barros, 2007, p. 89).

Dentre as transformações que o trabalho em saúde tem sofrido nas últimas décadas, principalmente no âmbito público, a atenção se volta para alguns pontos-chave geradores dos problemas atuais. As relações sociais de trabalho é um desses pontos. O Ministério da Saúde (Brasil, 2006) preconiza que os serviços devem ser estruturados mediante a integração dos diferentes profissionais, buscando um modo de organização do trabalho centrado em equipes multiprofissionais. São as chamadas equipes multiprofissionais de referência, esta no sentido de 'vínculo' a ser estabelecido com o usuário. Deseja-se também que essas equipes se configurem 'equipes colegiadas', ou seja, que planejem, avaliem e tomem decisões coletivamente, colocando em 
pauta o seu próprio trabalho e vivências, emitindo um 'olhar para dentro', sobre seu próprio processo e condições de trabalho, partindo então da sua realidade cotidiana para negociações e intervenções (Brasil, 2006; Campos, 2006).

Para que haja esse espaço aberto à livre discussão dos trabalhadores ('espaço de discussão'), é necessário confiança entre eles, pois representa um espaço onde podem ser formuladas de forma livre e pública opiniões por vezes contraditórias com o objetivo de proceder a arbitragens e de tomar decisões que interessam ao futuro do serviço e que dizem respeito ao futuro concreto de todos os membros que o constitui. É esse espaço de discussão aberto à deliberação coletiva que permite alcançar um consenso. No entanto, para que isso ocorra, é preciso que os sujeitos que aí intervêm possam compreender-se: falar para não dizer nada, falar sem a intenção de discutir ou ser discutido, escutar sem ouvir (Dejours, 1997).

Quando questionadas sobre a existência desse espaço para reunião da equipe e discussão das atividades e questões pertinentes ao funcionamento da ESF, poucas equipes relataram fazer uso de um momento como esse. As que faziam, informaram ser muito difícil reunir a equipe por completo. Os profissionais médicos e dentistas eram os que tinham maior dificuldade para estar presentes nas reuniões semanais. A justificativa para tal foi o desencontro entre os horários de trabalho na UBS desses profissionais. No entanto, apesar da ESF preconizar o cumprimento de devida carga horária, supõe-se que isso não está sendo cumprido nos municípios pesquisados, visto que a dificuldade dos pesquisadores em encontrar esses dois profissionais presentes nas unidades para a realização das entrevistas (individual e grupo focal) foi grande.

Sobre a autenticidade do que foi expresso nos grupos focais, do 'espaço de discussão' criado pelos pesquisadores, emergem interesses estratégicos em termos de poder que se acredita terem sido transpostos da organização do trabalho local para o grupo focal, não havendo uma relação de equidade entre os membros diante do espaço de discussão, o que compromete a autenticidade da palavra expressada. Na maior parte dos grupos focais, as relações de poder foram facilmente identificáveis, em sua maioria o autoritarismo, a postura hierarquizada do profissional, causadores de intimidação; medo e silêncio partiram do médico ao enfermeiro e deste último aos ACSs. De acordo com Dejours,

Em regra, a autenticidade só pode ser esperada se entre o ego que fala e o outro que escuta existe uma relação de equidade. Tomar a palavra para expressar publicamente as razões de agir comporta sempre um risco; esse risco só pode ser atenuado quando escutar representa também um risco: o de ser desestabilizado na sua análise, na sua compreensão e na sua opinião, ao considerar a opinião do outro (Dejours, 1997, p. 60). 
Durante os grupos focais, notou-se uma considerável homogeneidade no comportamento dos ACSs dos quatro municípios. Na entrevista coletiva, esse grupo de trabalhadores (sempre em maior número do que os outros profissionais) mostrava-se apático, calado e inibido. Dejours (1987) ressalta que a ausência de comentários na discussão e expressão do grupo pode haver um valor significativo se tivermos como referência a relação sofrimento-defesa. Portanto, se o comentário desaparece, é porque há um dispositivo defensivo estabelecido para lutar contra a percepção, contra o patético, o sofrimento; seria a chamada 'negação da percepção'. Além da intimidação que o grupo de ACSs parecia sofrer por parte de outros trabalhadores da ESF, o que revela a falta de equidade na equipe, confirmando a transposição das relações de poder do ambiente de trabalho para o grupo focal.

\section{Considerações finais}

Esta pesquisa visou essencialmente à vivência subjetiva, considerando como principal carreador o comentário em sua dimensão que engendra concepções subjetivas, hipóteses e interpretações do trabalhador acerca da relação com a atividade produtiva.

A partir do momento em que se reúne, à solicitação, um coletivo em função do que se deseja pesquisar, o grupo, ao se formar, provoca efeitos sobre a situação, até mesmo sobre as relações sociais na organização do trabalho. A pesquisa constitui-se, portanto, sempre como uma pesquisa-ação, em que o grupo homogêneo é definido, na verdade, pelas categorias subjetivas, ou seja, pelo objetivo de sustentar a solicitação de análise e compreensão de sua relação psíquica com o trabalho.

Partindo da concepção de que cada trabalhador é gestor de seu próprio trabalho, torna-se necessário vislumbrar o potencial gerador de mudanças a partir do trabalho cotidiano, mobilizando equipe e sujeitos em torno da reflexão sobre seu próprio 'fazer' (Santos-Filho e Barros, 2007).

$\mathrm{O}$ 'estado de segredo selado na vivência' esconde uma modalidade particular de existência do saber, a de somente existir na vivência coletiva do trabalho e de dissolver-se assim que há interesse pela vivência individual, mas que, para ser acessado requer o recurso à palavra (discurso operário). Torna-se então necessário, através da palavra e dos sistemas defensivos, uma leitura do sofrimento operário. É preciso ouvir e interpretar/desmascarar o sofrimento que é insidioso e silencioso. 


\section{Colaboradores}

Marilise Katsurayama redigiu o artigo e contribuiu com o levantamento bibliográfico, coleta, análise e discussão dos dados. Rosana Cristina Pereira Parente participou da análise dos dados e fez a revisão do texto final do artigo. Rodrigo Otávio Moretti-Pires contribuiu com a coleta de dados, análise, discussão e revisão do texto final do artigo. Os autores declaram que não há conflitos de interesse.

Resumen Este artículo trae un análisis de la relación trabajo-subjetividad en la Estrategia Salud de la Familia en el interior del estado de Amazonas, Brasil, bajo la perspectiva de la psicodinámica del trabajo, según la cual el trabajo es aquello que demanda, además del saber hacer, compromiso del cuerpo y movilización de la inteligencia, la capacidad de reflexionar, crear e inventar. Se propuso, a partir de allí, un análisis de lo que es invisible en el trabajo, en base a los diálogos con 75 profesionales de la salud en la Estrategia Salud de La Familia de cuatro municipios del Estado de Amazonas (Coari, Manacapuru, Parintins y São Gabriel da Cachoeira), obtenidas por medio de entrevistas individuales, grupos focales y observación participante. Se identificaron diferentes contenidos significativos del trabajo, o sea, el sentido simbólico que éste introduce en su actividad de trabajo, además de estrategias defensivas para la medición del sufrimiento, entre ellas la racionalización y la relación de confianza y cooperación encontradas en el equipo. Los trabajadores de la Estrategia Salud de la Familia en la Amazonia mostraron enfrentar problemas peculiares en cuanto a los servicios de salud de esos lugares. Por medio de esa encuesta cualitativa, pudimos dar voz al trabajador, considerándolo como el principal gestor de su propio trabajo, permitiendo a través de la reflexión vislumbrar su potencial de generar cambios a partir del trabajo cotidiano. Palabras clave trabajadores; servicios de salud; salud de la familia.

\section{Notas}

1 Associação Paulista para o Desenvolvimento da Medicina, Hospital São Paulo, São Paulo, Brasil.

$<$ marilise_k@hotmail.com>

Correspondência: Rua Doutor José Gomes Vieira, 391, Bairro Independência, CEP 12031-180, Taubaté, São Paulo, Brasil.

2 Universidade Federal do Amazonas, Instituto de Ciências Exatas, Amazonas, Manaus, Brasil.

$<$ rparente@ufam.edu.br>

3 Universidade Federal de Santa Catarina, Departamento de Saúde Pública, Florianópolis, Santa Catarina, Brasil. $<$ rodrigomoretti@ccs.ufsc.br> 
4 Artigo elaborado com base na dissertação de mestrado Trabalho e Saúde da Família: uma análise dejouriana da saúde do trabalhador no interior do estado do Amazonas, de autoria de Marilise Katsurayama, apresentada ao Programa de Pós-Graduação em Saúde, Sociedade e Endemias na Amazônia, Universidade Federal do Amazonas, Universidade Federal do Pará, Fundação Oswaldo Cruz, em fevereiro de 2010. A pesquisa foi financiada pela Fundação de Amparo a Pesquisa do Estado do Amazonas.

\section{Referências}

BECK, Carmem L. C. Da banalização do sofrimento à sua ressignificação ética na organização do trabalho. 2000. 260 fls. Tese (Doutorado em Enfermagem). Universidade Federal de Santa Catarina, Florianópolis, 2000.

BRASIL. Ministério da Saúde. A implantação da Unidade de Saúde da Família. Brasília, DF: Secretaria de Políticas de Saúde, Departamento de Atenção Básica, 2000.

BRASIL. Ministério da Saúde. Cartilha da $P N H$ : Equipe de referência e apoio matricial. Brasília: Ministério da Saúde, 2006.

CAMPOS, Gastão W. S. Clínica e saúde coletiva compartilhadas: teoria paideia e reformulação ampliada do trabalho em saúde. In: CAMPOS, Gastão W. S.; MINAYO, Maria C. S.; AKERMAN, Marco; DRUMOND, Marcos J.; CARVALHO, Yara M. (orgs.). Tratado de Saúde Coletiva. São Paulo: Hucitec; Rio de Janeiro: Editora Fiocruz, 2006.

COHN, A. Saúde da Família e SUS: convergências e dissonâncias. Rio de Janeiro: Beco do Azougue; São Paulo, Cedec, 2009.

DEJOURS, Christophe; ABDOUCHELI, E.; JAYET, C. Psicodinâmica do trabalho: contribuições da escola dejouriana à análise da relação prazer, sofrimento e trabalho. São Paulo: Atlas, 1994.
DEJOURS, Christophe. A loucura do trabalho: estudo da psicopatologia do trabalho. São Paulo: Cortez/Oboré, 1987.

DEJOURS, Christophe. O fator humano. Rio de Janeiro: Editora da FGV, 1997.

DEJOURS, Christophe. Subjetividade, trabalho e ação. Revista Produção, São Paulo, v. 14, n. 3, p.27-34, 2004.

DEJOURS, Christophe. Addendum da psicopatologia à psicodinâmica do trabalho. In: LANCMAN, Selma; SZNELWAR, Laerte I. (orgs.). Christophe Dejours: da psicopatologia à psicodinâmica do trabalho. Rio de Janeiro: Fiocruz, 1993.

FERREIRA, Mário C.; MENDES, Ana M. “Só de pensar em vir trabalhar, já fico de mau humor": atividade de atendimento ao público e prazer-sofrimento no trabalho. Revista Estudos de Psicologia, Natal, v. 6, n. 1, p. 97-108, 2001 .

FERREIRA, Mário C.; MENDES, Ana M. Trabalho e riscos de adoecimento: o caso dos auditores-fiscais da previdência social brasileira. Brasília: Fenafisp, 2003.

INSTITUTO BRASILEIRO DE GEOGRAFIA E ESTATÍSTICA (IBGE). Cidades@: Amazonas, infográficos. 2008. Disponível em: 
$<$ www.ibge.gov.br/cidadesat/xtras/perfil. php?lang $=\& \operatorname{cod}$ mun $=130120 \&$ search $=$ amazonas>. Acesso em: 2 de dez. 2009

LEWIN, Kurt. Intelligence and motivation. New York: Yearbook of the National Society for studies and Education, 1940.

MENDES, Ana M. Psicodinâmica do trabalho, São Paulo: Casa do Psicólogo, 2007.

MENDONZA-SASSI, Raúl; BÉRIA, Jorge U.; BARROS, Aluísio J. D. Outpatient health service utilization and associated factors: a population-based study. Revista de Saúde Pública, São Paulo, v. 37, n. 3, p. 372-8, 2003.

MINAYO, Maria C. S. (org.). Pesquisa social: teoria, método e criatividade. Rio de Janeiro: Vozes, 1996.

MORRONE, Carla F. 'Só para não ficar desempregado': ressignificando o sofrimento psíquico no trabalho: estudo com trabalhadores em atividades informais. 2001. 140fls. Dissertação (Mestrado em Psicologia) - Universidade de Brasília, Brasília, 2001.
RONZANI, Telmo M. O PSF e a saúde mental: uma proposta de saúde ampliada em Rio Pomba-MG. In: ENCONTRO NACIONAL DE PSICOLOGIA SOCIAL, 11., 2001, Florianópolis. Anais. Recife: Abrapso, 2001.

SAINT-GIRONS, Baldine. Motivation. Encyclopedia Universalis, Paris, v. 11, n. 1, p. 397-8, 1968.

SANTOS-FILHO, Serafim B.; BARROS, Maria E. B. de. Trabalhador da saúde: muito prazer! Protagonismo de trabalhadores na gestão do trabalho em saúde. Ijuí: Editora Unijuí, 2007.

Recebido em 14/03/2013

Aprovado em 11/02/2015 